\title{
Mineralogy in Geochemical modelling Role of Sulfide oxidation and Secondary Minerals in the attenuation of Metals and Metalloids
}

\author{
ROBERT BOWELL ${ }^{1}$, JULIEN DECLERCQ ${ }^{1}$ AND \\ HEATHER E. JAMIESON ${ }^{2}$
}

${ }^{1}$ SRK Consulting

${ }^{2}$ Queen's Universtiy

Presenting Author: rbowell@srk.co.uk

In natural and anthropogenic mine settings, oxidation of sulfides produce thermodynamically more stable secondary mineral phases. These minerals are an important control on the mobility on environmental mobility. Utilizing mineralogical observations and trace element chemistry the textural, paragenetic, and stability relations of several common sulfides and associated secondary phases have been studied. These have also been evaluated using PHREEQC reaction modelling and inverse modelling exercise in an attempt to explain the behaviour of major and trace elements.

Pyrite is the most ubiquitious of all sulfide minerals and is known to be a strong control on arsenic. Work in the Cobalt mining district has also identified its role as being important on nickel, cobalt, cadmium and zinc.

Sphalerite oxidation is one of the slowest of all sulfides except where there is high trace $\mathrm{Fe}$ present. Sphalerite oxidation in samples from central Wales shows a strong control on $\mathrm{Cd}$ and $\mathrm{Hg}$ and also several trace elements such as Tl, In , Ge, Ga and Sn. In carbonate environments carbonate mineral precipitation controls $\mathrm{Zn}$ chemistry but in the examples studied to date $\mathrm{Zn}$ occurs as a trace component of other carbonate minerals, notably aragonite.

Galena oxidation can produce a variety of lead minerals including pyromorphite, cerussite and anglesite. Trace elements associated with galena can also be incorporated into these minerals and include As, V, Sb, Sn, Tl and Bi.

Thermodynamic models of various fluid evolution paths using PHREEQC show the influence of temperature, $\mathrm{pH}$, variable PCO2, water chemistry, gangue mineralogy and/or different mineral reactions on the sequence of formation and stability of the secondary phases. Already small changes in one or more of these parameters can lead to different mineral assemblages or sequences of secondary minerals. This work has important implications for ore genesis studies and incorporation of trace elements and controls in geochemical models. 